14

\title{
Термодинамический анализ стабильности структуры однодоменного терапевтического антитела
}

\author{
(C) И.Е. Елисеев ${ }^{1}$, А.Н. Юденко ${ }^{1}$, Н.А. Беседина ${ }^{1}$, А.Б. Улитин ${ }^{2}$, \\ В.М. Екимова ${ }^{2}$, С.Р. Евдокимов ${ }^{2}$, Ю.В. Путинцева ${ }^{2}$, \\ П.А. Яковлев ${ }^{2}$, М.И. Ломовская ${ }^{2}$, И.Н. Тертеров ${ }^{1}$, \\ А.А. Богданов ${ }^{1}$, М.В. Дубина ${ }^{3}$
}

${ }^{1}$ Санкт-Петербургский национальный исследовательский академический университет РАН,

2 ЗАО „Биокад“, Санкт-Петербург

${ }^{3}$ Первый Санкт-Петербургский государственный медицинский университет им. акад. И.П. Павлова

E-mail: eliseev@spbau.ru

Поступило в Редакцию 1 сентября 2017 г.

Стабильность нового однодоменного терапевтического антитела к рецептору ErbB3 исследована методом спектроскопии флуоресценции при различных концентрациях денатурирующего вещества и температуре. Анализ экспериментальных кривых денатурации позволил построить полную термодинамическую модель процесса денатурации и определить все параметры перехода: $\Delta G=8.5 \mathrm{kcal} \cdot \mathrm{mol}^{-1}, T_{m}=76^{\circ} \mathrm{C}, \Delta H_{m}==107 \mathrm{kcal} \cdot \mathrm{mol}^{-1}$, $\Delta C_{p}=1.8 \mathrm{kcal} \cdot \mathrm{K}^{-1} \cdot \mathrm{mol}^{-1}$. Полученные данные свидетельствуют о высокой стабильности антитела в широком диапазоне условий, что чрезвычайно важно для дальнейших структурно-функциональных исследований и возможного терапевтического применения.

DOI: 10.21883/PJTF.2017.23.45280.17022

Важными мишенями при терапии онкологических заболеваний являются рецепторные тирозинкиназы ErbB1-4 [1]. Моноклональные антитела, блокирующие рецепторы ErbB1 и ErbB2, успешно используются в терапии уже два десятка лет. Однако в последнее время появились экспериментальные свидетельства того, что третий член семейства, рецептор ErbB3, ответствен за развитие резистентности при терапии ингибиторами ErbB1-2 [2]. Вследствие этого существует необходимость разработки новых терапевтических антител к рецептору ErbB3, которые 
позволят преодолеть проблему резистентности за счет одновременного блокирования ErbB1/2 и ErbB3.

В настоящее время уже более десятка антител к ErbB3 находятся на разных стадиях клинических испытаний [3]. В России разработкой антител к ErbB3 занимается компания „Биокад“, при этом используются особые неканонические одноцепочечные тела, встречающиеся у представителей семейства верблюдовых (Camelidae) [4]. Преимуществами таких одноцепочечных антител являются высокая аффинность, повышенная стабильность и простота биотехнологического производства. Путем иммунизации лам и последующего отбора при помощи фагового дисплея компанией „Биокад“ был получен ряд одноцепочечных антител к ЕrbB3.

Стабильность структуры является важнейшей характеристикой белкового терапевтического препарата. Термическая стабильность и стабильность к химической денатурации тесно связаны с агрегационной способностью и адсорбцией на различных поверхностях и критически важны при получении, очистке и хранении препарата, а также его терапевтическом применении [5]. В настоящей работе нами проведен полный термодинамический анализ вариабельного фрагмента одноцепочечного антитела (VHH-1) к III внеклеточному домену рецептоpa ErbB3, ранее отобранного в компании „Биокад“ для дальнейшей разработки.

С физической точки зрения термодинамика денатурации глобулярного белка может быть описана моделью двух состояний

$$
F \stackrel{\Delta G(T)}{\longleftrightarrow} U, \quad F+U=1, \quad U=F \exp \left(\frac{-\Delta G(T)}{R T}\right),
$$

где $F$ обозначает долю молекул белка в нативном состоянии, $U-$ в денатурированном состоянии, $\Delta G(T)$ - свободная энергия денатурации. Используя уравнение Гиббса-Гельмгольца и соотношение $\Delta H(T)=\int_{T_{m}}^{T} \Delta C_{p} d T=\Delta H_{m}+\Delta C_{p}\left(T-T_{m}\right)$, можно получить следующее уравнение для зависимости свободной энергии от температуры:

$$
\Delta G(T)=\Delta H_{m}\left(1-\frac{T}{T_{m}}\right)+\Delta C_{p}\left(T-T_{m}-T \ln \frac{T}{T_{m}}\right),
$$

параметрами перехода являются температура плавления $T_{m}\left(\Delta G\left(T_{m}\right)=\right.$ $=0)$, энтальпия перехода $\Delta H_{m}$ и изменение теплоемкости $\Delta C_{p}$, которое считается не зависящим от температуры.

Письма в ЖТФ, 2017, том 43, вып. 23 
При нормальных условиях равновесие (1) сильно сдвинуто в сторону нативного состояния и доля денатурированного белка чрезвычайно мала, что затрудняет определение свободной энергии. Классическим биохимическим приемом для того, чтобы сдвинуть равновесие и сделать возможным количественный анализ перехода, является добавление денатурирующего вещества, например мочевины [6]. Для глобулярных белков свободная энергия денатурации линейно зависит от концентрации мочевины [7]

$$
\Delta G(T,[\text { Urea }])=m\left([\text { Urea }]_{1 / 2}(T)-[\text { Urea }]\right),
$$

где $m$ - коэффициент зависимости от концентрации мочевины, $[$ Urea $]$ - концентрация мочевины, $[\text { Urea }]_{1 / 2}(T)-$ концентрация мочевины в середине кривой денатурации при данной температуре. Дальнейшая экстраполяция к нулевой концентрации денатурирующего вещества позволяет получить искомое значение $\Delta G(T)$.

Для проведения термодинамического анализа нами был получен и очищен рекомбинантный вариабельный фрагмент одноцепочечного антитела к ErbB3, аминокислотная последовательность которого указана в таблице. Вкратце, генетическая конструкция на основе вектора pЕT22b (Novagen), кодирующая антитело с С-концевым гистидиновым тагом, была использована для трансформации клеток E.coli BL21(DE3). Белок был очищен при помощи аффинной хроматографии на Ni-NTA и ионообменной хроматографии на колонке MonoQ по стандартным протоколам, чистота белка составила не менее 95\% по данным электрофореза в полиакриламидном геле (данные не приведены). Затем была приготовлена серия растворов белка $(0.07 \mathrm{mg} / \mathrm{ml})$ в $50 \mathrm{mM} \mathrm{Na} \mathrm{HPO}_{4}$ $(\mathrm{pH}=8.0)$ с различными концентрациями мочевины от 0 до $10 \mathrm{M} \mathrm{c}$ шагом $0.25 \mathrm{M}$.

Для определения доли денатурированного белка нами проводились измерения флуоресценции аминокислотных остатков триптофана в исследуемом антителе в диапазоне 300-500 nm при возбуждении светом с длиной волны $280 \mathrm{~nm}$ на спектрометре Chirascan (Applied Photophysics). Спектр триптофановой флуоресценции чувствителен к структурным изменениям в белке и сдвигается в длинноволновую область, меняет форму и интенсивность при денатурации (рис. 1), что было использовано для расчета долей нативного и денатурированного антител. Для каждого спектра флуоресценции нами был рассчитан 


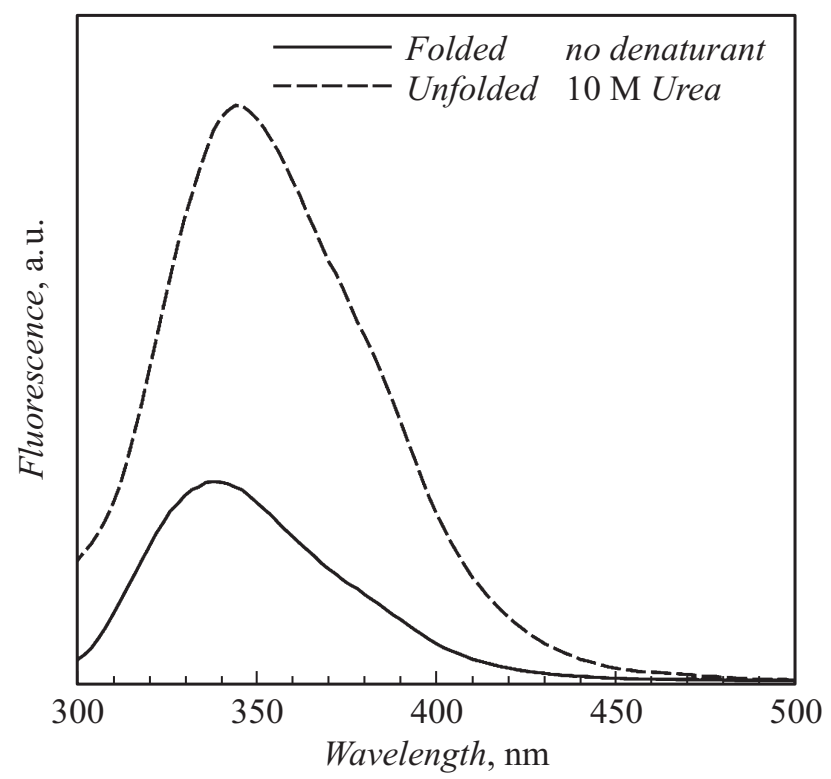

Pис. 1. Спектры флуоресценции однодоменного антитела VHH-1 в нативном и полностью денатурированном состоянии $\left(T=20^{\circ} \mathrm{C}\right)$. Посредством анализа спектров флуоресценции в зависимости от концентрации мочевины были определены доли нативного и денатурированного белка и построены кривые денатурации для различных температур.

коэффициент асимметрии $S$ распределения интенсивности. Затем кривая денатурации белка была построена как зависимость $S$ от концентрации мочевины. Для определения коэффициента $m$ и величины $[\text { Urea }]_{1 / 2}$ кривая денатурации была аппроксимирована следующей функцией:

$$
S=\frac{S_{F}+S_{U} \exp \left(\frac{-m\left([\text { Urea }]_{1 / 2}-[\text { Urea }]\right)}{R T}\right)}{1+\exp \left(\frac{-m\left([\text { Urea }]_{1 / 2}-[\text { Urea }]\right)}{R T}\right)},
$$

где $S_{F}$ и $S_{U}-$ величины $S$ для нативного и денатурированного состояний, $S=F S_{F}+U S_{U}$, аппроксимация проводилась нелинейным 


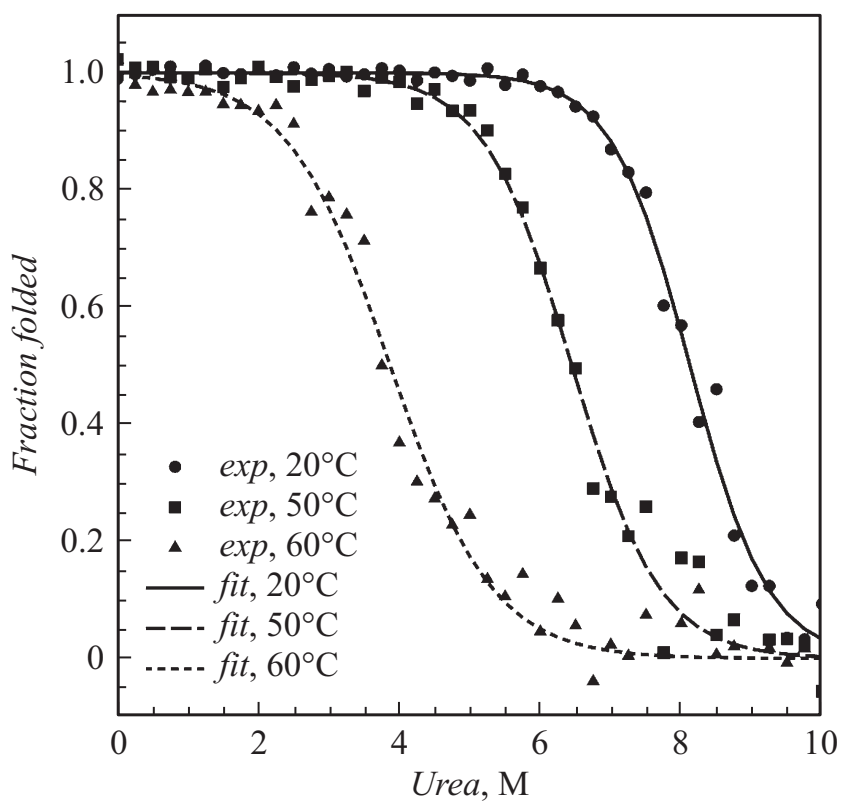

Рис. 2. Кривые денатурации однодоменного антитела VHH-1 мочевиной для нескольких температур. Аппроксимация кривых уравнением (4) позволила определить коэффициент $m$, параметр $[U r e a]_{1 / 2}$ и получить $\Delta G$ для каждой температуры.

методом наименьших квадратов. Таким образом были измерены спектры флуоресценции и проведен анализ для всей серии образцов с различными концентрациями мочевины в температурном диапазоне $10-65^{\circ} \mathrm{C}$. Экспериментальные данные и аппроксимации функцией (4) для нескольких температур приведены на рис. 2.

После получения экспериментальных значений $\Delta G(T)$ из кривых денатурации для разных температур мы воспользовались уравнением Гиббса-Гельмгольца (2) для определения параметров $\Delta H_{m}, \Delta C_{p}$ и $T_{m}$ (рис. 3); найденные величины приведены в таблице. Как видно из рис. 3, экспериментальные данные хорошо описываются уравнением (2), которое позволяет предсказывать стабильность антитела в широких диапазонах температур и условий среды. Полученные вели-

Письма в ЖТФ, 2017, том 43, вып. 23 
Значения термодинамических величин, полученные в результате анализа кривых денатурации и температурной зависимости свободной энергии денатурации

\begin{tabular}{|c|c|c|c|c|c|c|c|}
\hline Белок & $\begin{array}{c}\text { Аминокислотная } \\
\text { последовательность }\end{array}$ & $\begin{array}{c}\langle m\rangle, \\
\mathrm{kcal} \cdot \mathrm{mol}^{-1} \cdot \mathrm{M}^{-1}\end{array}$ & $\begin{array}{c}{\left[\text { Urea }_{1 / 2}\right.} \\
\mathrm{M} \\
\left(20^{\circ} \mathrm{C}\right)\end{array}$ & $\begin{array}{c}\Delta G \\
\mathrm{kcal} \cdot \mathrm{mol}^{-1} \\
\left(20^{\circ} \mathrm{C}\right)\end{array}$ & $\begin{array}{c}\Delta H_{m}, \\
\mathrm{kcal} \cdot \mathrm{mol}^{-1}\end{array}$ & $\mid \begin{array}{c}\Delta C_{p}, \\
\mathrm{kcal} \cdot \mathrm{K}^{-1} \cdot \mathrm{mol}^{-1}\end{array}$ & $\begin{array}{l}T_{m}, \\
{ }^{\circ} \mathrm{C}\end{array}$ \\
\hline $\begin{array}{l}\text { VHH- } \\
1-\mathrm{His}_{6}\end{array}$ & $\begin{array}{l}\text { EVQLVQSGGGLVQPGGSLRLS } \\
\text { CAASGRTSSKYAMGWFRQAP } \\
\text { GKGTEFVATISWSDGSTYYAD } \\
\text { SVEGRFTISRDNAKNTVYLQM } \\
\text { NSLKPEDTAVYYCAAAVDVLA } \\
\text { GTFEYEYDYWGQGTLVTVSSH } \\
\text { HHHHH }\end{array}$ & $1.04 \pm 0.09$ & $8.12 \pm 0.05$ & $8.5 \pm 0.6$ & $107 \pm 9$ & $1.8 \pm 0.5$ & $\begin{array}{l}76 \pm 2 \\
75 \pm 1 \\
(\mathrm{DSC})\end{array}$ \\
\hline
\end{tabular}




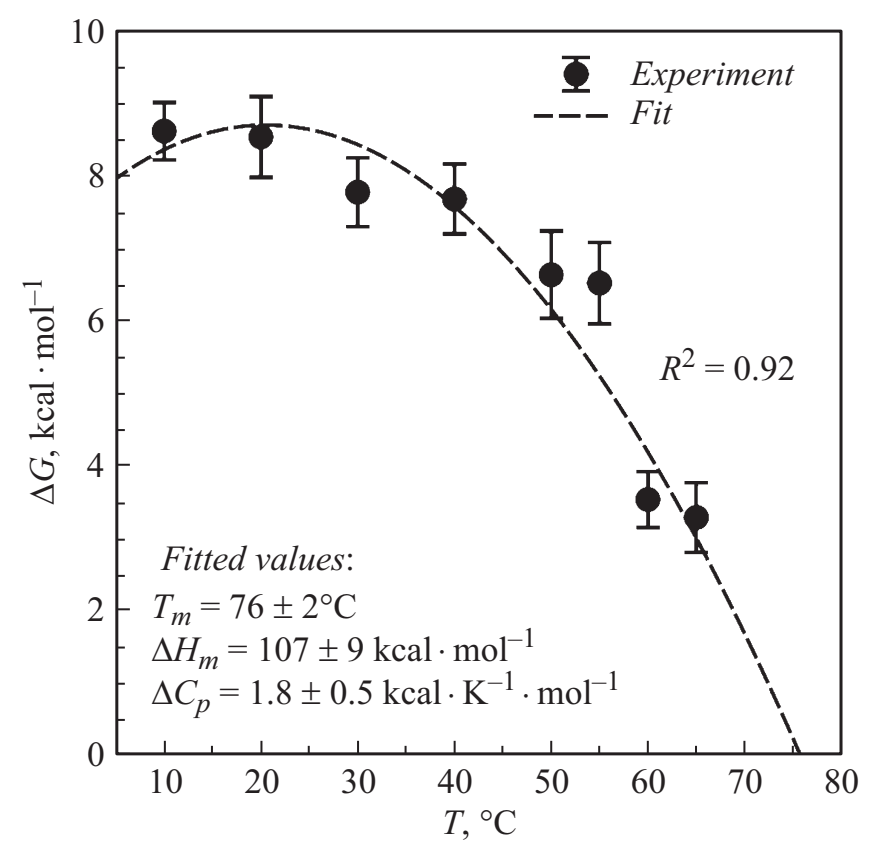

Рис. 3. Экспериментальная зависимость свободной энергии денатурации от температуры и ее аппроксимация уравнением Гиббса-Гельмгольца (2). В результате аппроксимации получены термодинамические параметры перехода $\Delta H_{m}, \Delta C_{p}$ и $T_{m}$.

чины $\Delta G=8.5 \mathrm{kcal} \cdot \mathrm{mol}^{-1}\left(20^{\circ} \mathrm{C}\right)$ и $T_{m}=76^{\circ} \mathrm{C}$ свидетельствуют о чрезвычайно высокой стабильности исследуемого антитела (в сравнении со средними значениями для белков подобного размера у различных живых организмов [8]).

Для проверки предсказаний модели нами было проведено независимое измерение температуры плавления антитела методом дифференциальной сканирующей калориметрии на приборе nanoDSC (TA Instruments). Значение температуры плавления $T_{m}^{\mathrm{DSC}}=75 \pm 1^{\circ} \mathrm{C}$ было получено по положению пика теплоемкости (график не приведен) и замечательно согласуется со значением, установленным на основе спектрометрических экспериментов. Как видно из уравнения (2) и

Письма в ЖТФ, 2017, том 43, вып. 23 
рис. 3, свободная энергия денатурации является выпуклой функцией температуры и существует два значения температуры, при которых свободная энергия денатурации равна нулю. Холодовая денатурация, когда структура нарушается не при нагревании, что вполне ожидаемо, а при охлаждении, является общей закономерностью для глобулярных белков [9]. В данном случае температура перехода, полученная решением уравнения (2) с найденными параметрами, равна $-30^{\circ} \mathrm{C}$. Таким образом, исследуемый белок также стабилен при охлаждении в широкой области температур, типичных для биохимических экспериментов.

В заключение отметим, что в настоящей работе нами была исследована стабильность нового однодоменного антитела к рецептору ErbB3. Анализ кривых денатурации позволил найти зависимость свободной энергии денатурации от температуры и определить все термодинамические параметры перехода: энтальпию плавления, изменение теплоемкости, температуру плавления, а также предсказать температуру холодовой денатурации. Полученные данные свидетельствуют о высокой термодинамической стабильности белка в широком диапазоне условий, что чрезвычайно важно для дальнейших структурных и функциональных исследований, а в перспективе и для возможного терапевтического применения.

Работа выполнена при поддержке Министерства образования и науки РФ (уникальный идентификатор RFMEFI57716Х0217, соглашение № 14.577.21.0217).

\section{Список литературы}

[1] Поляновский О.Л., Лебеденко Е.Н., Деев С.М. // Биохимия. 2012. Т. 77. В. 3. C. 289-311.

[2] Kol A., van Scheltinga A.G.T., Timmer-Bosscha H., Lamberts L.E., Bensch F., de Vries E.G.E., Schröder C.P. // Pharmacol. Ther. 2014. V. 143. P 1-11.

[3] Zhang N., Chang Y., Rios A., An Z. // Acta Biochim. Biophys. Sinica. 2015. V. 48. P. 39-48.

[4] Hamers-Casterman C.T.S.G., Atarhouch T., Muyldermans S., Robinson G., Hammers C., Songa E.B., Bendahman N., Hammers R. // Nature. 1993. V. 363. P. 446-448.

Письма в ЖТФ, 2017, том 43, вып. 23 
[5] Manning M.C., Chou D.K., Murphy B.M., Payne R.W., Katayama D.S. // Pharm. Res. 2010. V. 27. P. 544-575.

[6] Shaw K.L., Scholtz J.M., Pace C.N., Grimsley R.G. // Protein structure, stability, and interactions / Ed. J. Shriver. Methods in molecular biology. V. 490. Humana Press, 2009. P. 41-55.

[7] Myers J.K., Pace C.N., Scholtz J.M. // Protein Sci. 1995. V. 4. P. 2138-2148.

[8] Ghosh K., Dill K. // Biophys. J. 2010. V. 99. P. 3996-4002.

[9] Privalov P.L. // Crit. Rev. Biochem. Mol. Biol. 1990. V. 25. P. 281-306. 